Pesq. Vet. Bras. 35(10):853-858, outubro 2015 DOI: 10.1590/S0100-736X2015001000006

\title{
Cardiothoracic ratio and vertebral heart size (VHS) to standardize the heart size of the tufted capuchin (Cebus apella Linnaeus, 1758) in computerized radiographic images ${ }^{1}$
}

\author{
Hermínio J. Rocha-Neto ${ }^{2}$, Laecio da Silva Moura², Gerson T. Pessoa ${ }^{2}$, Carlos E. \\ Ambrósio $^{3}$, Francisco C.A. Sousa ${ }^{2}$, Renan P.S. Rodrigues ${ }^{4}$, Porfírio C. Guerra ${ }^{5}$ \\ and Flávio R. Alves ${ }^{6 *}$
}

\begin{abstract}
Rocha-Neto H.J., Moura L.S., Pessoa G.T., Ambrósio C.E., Sousa F.C.A., Rodrigues R.P.S., Guerra P.C. \& Alves F.R. 2015. Cardiothoracic ratio and vertebral heart size (VHS) to standardize the heart size of the tufted capuchin (Cebus apella Linnaeus, 1758) in computerized radiographic images. Pesquisa Veterinária Brasileira 35(10):853-858. Departamento de Morfofisiologia Veterinária, Universidade Federal do Piauí, Campus Universitário Ministro Petrônio Portella, Bairro Ininga, Teresina, PI 64049-550, Brazil. E-mail: flavioribeiro@ufpi.edu.br

The VHS and CTR were assessed using computerized thoracic radiographs of ten clinically healthy tufted capuchin monkeys (five males and five females) from the Wild Animal Screening Center in São Luís (Centro de Triagem de Animais Silvestres de São Luís-MA-CETAS). Radiographs were taken in laterolateral and dorsoventral projections to calculate the cardiothoracic ratio (VHS) and vertebral heart size (CTR). The VHS showed mean values of $9.34 \pm 0.32 \mathrm{v}$ (males) and $9.16 \pm 0.34 \mathrm{v}$ (females) and there was no statistical difference between males and females ( $p>0.05)$. The CTR showed mean values of $0.55 \pm 0.04$ (males) and $0.52 \pm 0.03$ (females) and there was no statistical difference between the sexes ( $p>0.05)$. There was positive correlation between VHS and CTR $(r=0.78)$. The thoracic and heart diameters showed mean values of $5.70 \pm 0.48 \mathrm{~cm}$ and $2.16 \pm 0.40 \mathrm{~cm}$ in the males, respectively. In the females they measured $5.32 \pm 0.39 \mathrm{~cm}$ and $2.94 \pm 0.32 \mathrm{~cm}$. There was no statistical difference between the sexes. Our results show that the high correlation found between VHS and CTR permitted the verification with similar clinical precision between the two methods to estimate alterations in the heart silhouette by radiographic examination of tufted capuchin, making it an easy technique to apply that can be considered in the investigation of heart problems for this wild species.
\end{abstract}

INDEX TERMS: CTR, VHS, heart silhouette, cutia, Cebus apella, wild animals.

RESUMO.- [Índice cardiotorácico e vertebral heart size (VHS) para a padronização do tamanho cardíaco do macaco-prego (Cebus apella Linnaeus, 1758) em imagens radiográficas computadorizadas.] Para a ava-

\footnotetext{
${ }^{1}$ Received on October 1, 2014.

Accepted for publication on August 10, 2015.

${ }^{2}$ Programa de Pós-Graduação em Ciência Animal, Universidade Federal do Piauí (UFPI), Teresina, PI 64049-550, Brazil.

${ }^{3}$ Departamento de Medicina Veterinária, Universidade de São Paulo (USP), Pirassununga, SP 13635-900, Brazil

${ }^{4}$ Programa de Iniciação Científica (CNPq), UFPI, Teresina, PI 64049-550.

${ }^{5}$ Departamento das Clínicas, Universidade Estadual do Maranhão (UEMA), Campus Paulo VI s/n, Cx. Postal 9, São Luís, MA 65055-310, Brazil.

6 Departamento de Morfofisiologia Veterinária, UFPI, Teresina, PI 64049-550.*Corresponding author: flavioribeiro@ufpi.edu.br
}

liação do VHS e ICT foram utilizadas radiografias torácicas computadorizadas de 10 macacos-prego $(05$ machos e 05 fêmeas) clinicamente saudáveis, oriundos do Centro de Triagem de Animais Silvestres de São Luís-MA-CETAS. Foram tomadas radiografias em projeções laterolaterais e dorsoventrais, para cálculo do Vertebral Heart Scale (VHS) e Índice Cardiotorácico (ICT). O VHS evidenciou valores médios de 9,34 $\pm 0,32 \mathrm{v}$ (machos) e 9,16 $\pm 0,34 \mathrm{v}$ (fêmeas), não ocorrendo diferença estatística entre machos e fêmeas $(p>0,05)$. O ICT evidenciou valores médios de $0,55 \pm 0,04$ (machos) e de 0,52 $\pm 0,03$ (fêmeas), não sendo verificada diferença estatística entre sexos $(p>0,05)$. Verificou-se correlação positiva entre VHS e ICT $(r=0,78)$. Os diâmetros torácico e cardíaco demonstraram valores médios de $5,70 \pm 0,48 \mathrm{~cm}$ e $3,16 \pm 0,40 \mathrm{~cm}$ nos machos, 
respectivamente. Nas fêmeas mediram $5,32 \pm 0,39 \mathrm{~cm}$ e $2,94 \pm 0,32 \mathrm{~cm}$. Não houve diferença estatística entre os sexos $(p>0,05)$. Os nossos resultados demonstraram que a alta correlação encontrada entre o VHS e o ICT permitiu verificar precisão clínica semelhante entre os dois métodos, para estimar alterações da silhueta cardíaca ao exame radiográfico de macacos-prego, constituindo-se como uma técnica de fácil aplicação, poddevendo ser considerada na investigação de problemas cardíacos para esta espécie silvestre.

TERMOS DE INDEXAÇÃO: ICT, VHS, silhueta cardíaca, cutia, Cebus apella, animais silvestres.

\section{INTRODUCTION}

Nonhuman primates have been reared to collect physiological and biological data for scientific purposes since 1932 by Dr. Carlos Chagas, improving the management of these animals, to carry out experiments related to disease diagnosis and treatment (Andrade et al. 2007). Nonhuman primates have been widely used as animal models in biomedical research (Yang et al. 2014), especially because of their anatomical and physiological characteristics that are similar to man, compared to other animal models (Nimri et al. 2014, Fukushima et al. 2014).

Thoracic $x$-rays are well-established in Veterinary Medicine as a non-invasive method of investigating the thoracic cavity in animals (Reichle \& Wisner 2000). In this context, radiographic images of the primate thorax can help elucidate pathological processes intrinsic to the species and help in the study of disease models, or further, for morphometric studies of interest to primatology (Lawler et al. 2006, Sharpe et al. 2010, Alves 2012).

The study of the normal pattern of thoracic x-rays in nonhuman primates is essential to characterize abnormalities that cause diseases in these animals. Although innumerable studies have been designed to establish both the assessment criteria and the definition of the morphometric parameters for several monkey species, such as Macaca nigra and Macaca tonkeana (Schillaci et al. 2009,2010), Macaca mulatta, Macaca fascicularis (Schillaci et al. 2010), Callithrix jacchus (Wagner \& Kirberger 2005) and the Rhesus monkey, only one study was found in the literature on the morphological aspects of the thoracic cavity in the tufted capuchin (Alves et al. 2012).

Cardiac indices such as the Vertebral Heart Size (VHS), already consolidated to estimate the size of the heart silhouette in small animals (Buchanan 2000, Litster \& Buchanan 2000) and the cardiothoracic ratio (CTR) widely used in medicine as a prediction of the heart function and life span of cardiac patients (Michiue et al. 2010, Hasan et al. 2012) are still only rarely used in nonhuman primate Veterinary Medicine.

In Veterinary Medicine, a mean value has been suggested for VHS for dogs between 10.5 vertebra (v) in radiographic projections (Lamb et al. 2001, Nakayama et al. 2001, Lamb \& Boswood 2002,). For nonhuman primates the values of $9.42 \pm 0.44 \mathrm{v}$ have been suggested for Callithrix jacchus (Wagner \& Kirberger 2005), 10.7 $\pm 0.69 \mathrm{v}$ for Aotus spp. (Knowlen et al. 2013), 9.63 $\pm 0.0 .45 \mathrm{v}$ for Chlorocebus sabaeus (Young et al. 2013) and $9.12 \pm 0.63 \mathrm{v}$ for Cebus apella (Alves et al. 2012). Values have been reported for the CTR from 0.55 (Schillaci et al. 2010) to 0.58 (Xie et al. 2014) for Macaca fascicularis, 0.59 for Macaca tonkeana and 0.58 for Macaca nigra (Schillaci et al. 2009).

To our knowledge there are no references to date on the CTR values for the tufted capuchin (Cebus apella), nor a comparison of this technique with other measuring techniques of the heart silhouette in thoracic x-rays, already applied in nonhuman primates. Thus, considering that the tufted capuchin (Cebus apella) is a typically South American animal and that there are no data referent to the measuring of the species, the objective of the present study was to generate thoracic biometric data of the cardiothoracic ratio that can help in clinical procedures, because these animals are constant frequenters of the Wild Animal Screening Centers (Centros de Triagem de Animais Silvetres-CETAS), due to involvement in accidents or predatory hunting. It is also hoped to aggregate information on the cardiovascular profile of the species as an animal model for studies of heart diseases in humans.

\section{MATERIALS AND METHODS}

\section{Animals}

Ten healthy tufted capuchin monkeys were used (Cebus apella), from the Wild Animal Screening Center (Centro de Triagem de Animais Silvestres (CETAS)) in São Luís-MA, Brazil. The animals were separated into groups, consisting of five males and five females with an average of two years of age. They were previously identified, weighed and submitted to clinical examination and hematological profile (Wirz et al. 2008). The experimental protocol was approved by the Brazilian Environmental Institute and the Renewable Natural Resources Institute (IBAMA-SISBIO), protocol number 02012.003909/2006.

\section{Anesthetic protocol}

The tufted capuchin were already in cages because they came from rehabilitation or apprehension by the CETAS. Later they were sedated using meperidine chlorhydrate (Meperidina ${ }^{\circledR}$, Agribands, $5 \mathrm{mg} / \mathrm{kg} / \mathrm{IM}$ ). After this moment, chemical containment continued with the association of xylazine chlorhydrate (Rompum $^{\circledR}$, Bayer do Brasil, $1 \mathrm{mg} / \mathrm{kg} / \mathrm{lM}$ ) and ketamine chlorhydrate $\left(\right.$ Ketalar $^{\circledR}$, Pfizer do Brasil, 40mg/kg/IM). The animals were kept under chemical containment using Propofol 1\% (Fresofol $^{\circledR}$, Fresenius Kabi, $5 \mathrm{mg} / \mathrm{kg} / \mathrm{IV}$ ) throughout the examination procedure. The heart and respiratory function was assessed using both a stethoscope to observe the normal heart sounds, respiratory frequency and air diffusion in the lung fields.

\section{Radiographic examination}

To carry out the radiographic examinations, the animals were placed in ventral and lateral decubitus to obtain radiographic images in dorsoventral and laterolateral projections of the thoracic region. An x Ray Tec $300 \mathrm{~mA}$ apparatus was used, installed in the Diagnostic Image Service from the Veterinary Hospital of the State University of Maranhão-UEMA. The apparatus was calibrated with a $1 \mathrm{~m}$ focus film-distance and exposure techniques of $45 \mathrm{kVp}$ and $0.1 \mathrm{mAs}$. The images were captured in a chassis containing $(18 \times 24 \mathrm{~cm}$, phosphorus plates, AGFA Health Care, São Paulo, Brazil). The chassis were read by an AGFA CR30-X digital image processor and saved for later assessment. 


\section{Measuring the VHS (Vertebral Heart Size)}

The VHS (Vertebral Heart Size) was measured according to the protocol established by Buchanan \& Bücheler (1995), Litster \& Buchanan (2000), that is the sum of the heart length and heart width at its greatest diameter and its later comparison with the vertebra bodies starting at T4 (Fig.1a). These measurements were taken and mean values were estimated to establish normality criteria. Because it is a wild species and in order to reduce the stress of containment and also knowing that the literature reports that there is no difference in the VHS values in animals between the right and left lateral decubitus (Litster \& Buchanan 2000), this experiment was carried out taking the right decubitus as the base for all the measurements.
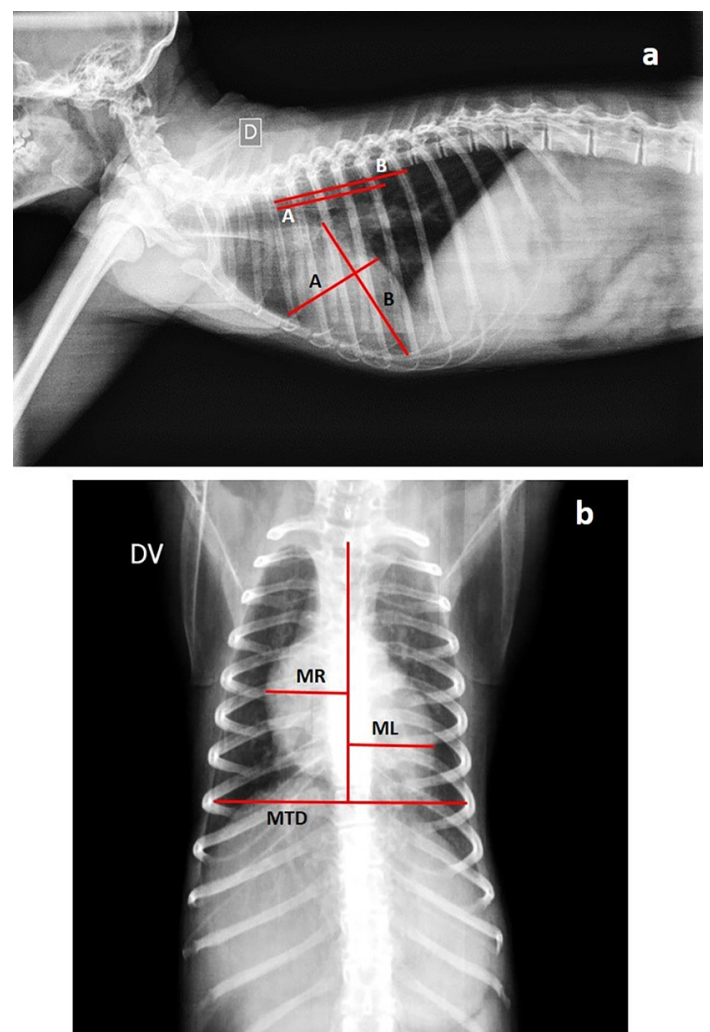

Fig.1. Digital radiographic image of the chest of a capuchin monkey. In (a) right laterolateral projection to obtain the calculation of VHS. In (b) dorsoventral projection to obtain the ICT. (A) Higher cardiac diameter. (B) Greater cardiac length. (MR + ML) represent the two largest distances from the vertical line that divides the right and left side of the heart.

\section{Vertebral heart size (CTR)}

The CTR was assessed by comparing the greatest widths of the heart silhouette and the distance between the thoracic walls at height T8, according to methodology described by Schillaci et al. (2009) for Macaca fascicularis and by Hasan et al. (2012) in humans. The heart width was measured at the two greatest distances (ML and MR) from the vertical line that divides the limits between the right and left side of the heart, at the point of its greatest diameter. Similarly, the thoracic width was measured at the point of greatest thoracic diameter (MTD), as follows:

$$
\mathrm{CTR}=\frac{\mathrm{MR}+\mathrm{ML}}{\mathrm{MTD}}
$$

For both the methods used, standardization was adopted so that the sections of thoracic x-rays were taken at the inspiration peak, to guarantee the greatest thoracic distension (Fig.1b).

\section{Statistics}

The data were submitted to the Shapiro-Wilk and Kolmogorov-Smirnov normality error test and later the means of the male and female groups (VHS and CTR) were analyzed by the paired student $t$ test, to interpret the parameters, considering a $5 \%$ confidence interval $(\mathrm{p}<0.05)$.

\section{RESULTS}

The studied animals presented heart silhouette situated between the third and fifth intercostal space, in the mid mediastinum. The VHS in the males showed a mean value of $9.34 \pm 0.32 \mathrm{v}$ and for the females, $9.16 \pm 0.34 \mathrm{v}$. When the VHS was assessed between males and females, there was no statistical difference $(\mathrm{p}>0.05)$. Thus, assuming there was no difference between males and females, the VHS was estimated for males and females as a mean value of $9.25 \pm 0.32 \mathrm{v}$ (Table 1).

Table.1. Comparative values measured for the Vertebral Heart Scale (VHS) and cardiothoracic ratio (CTR) in capuchin monkeys

\begin{tabular}{lc}
\hline Gender & $\begin{array}{c}\text { VHS } \\
\text { (right lateral recumbency) }\end{array}$ \\
\hline Male & $9,34 \pm 0,32^{\mathrm{a}}$ \\
Female & $9,16 \pm 0,34^{\mathrm{a}}$ \\
& CTR \\
Male & $0,55 \pm 0,04^{\mathrm{a}}$ \\
Female & $0,52 \pm 0,03^{\mathrm{a}}$
\end{tabular}

* Means followed by different letters in the same row differ statistically.

The vertebral heart size (CTR) presented a mean value of $0.55 \pm 0.03$ for the males and $0.55 \pm 0.04$ for the females and there was no statistical difference between the sexes (Table 1). Thus, calculating a CTR between males and females resulted in the average value of $0.55 \pm 0.04$. The correlations between the VHS and CTR were positive $(\mathrm{y}=0.1069 \mathrm{x}-0.4346$. $\mathrm{r}=0.78$ ), taking the CTR as dependent variable (Fig.2).

The study of the thoracic and heart diameter in the males showed average values of $5.70 \pm 0.48 \mathrm{~cm}$ and $2.16 \pm 0.40 \mathrm{~cm}$, respectively. In the females these values were $5.32 \pm 0.39 \mathrm{~cm}$ and $2.94 \pm 0.32 \mathrm{~cm}$. Assessment of the differences in the means of the thoracic and heart diameters showed no significant difference between males and females $(p>0.05)$ (Table 2).

\section{CTR versus VHS}

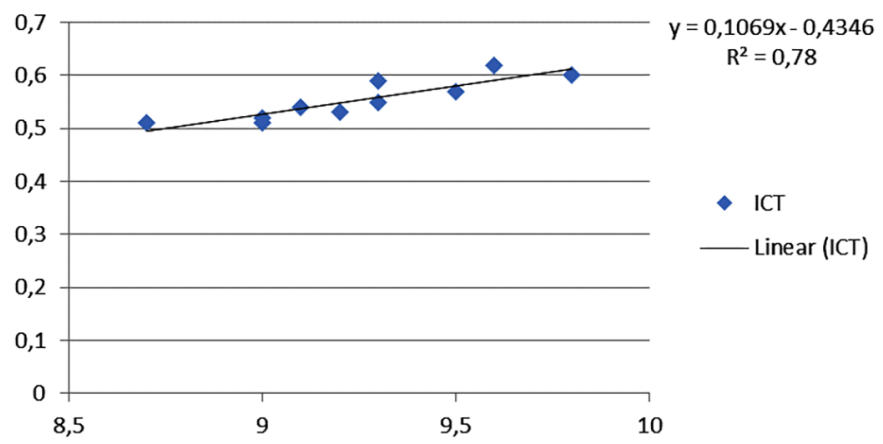

Fig.2. Linear correlation between VHS (right lateral recumbency) and Cardiothoracic ratio in capuchin monkeys. 
Table 2. Comparative values measured for cardiac and thoracic diameters between females and males in capuchin monkeys

\begin{tabular}{lcc}
\hline & Male & Female \\
\hline Thoracic Diameter & $5,70 \pm 0,48 \mathrm{a}$ & $5,32 \pm 0,39 \mathrm{a}$ \\
Cardiac Diameter & $3,16 \pm 0,40 \mathrm{a}$ & $2,94 \pm 0,32 \mathrm{a}$
\end{tabular}

* Means followed by different letters in the same row differ statistically.

\section{Thoracic Diameter (Male versus Female)}

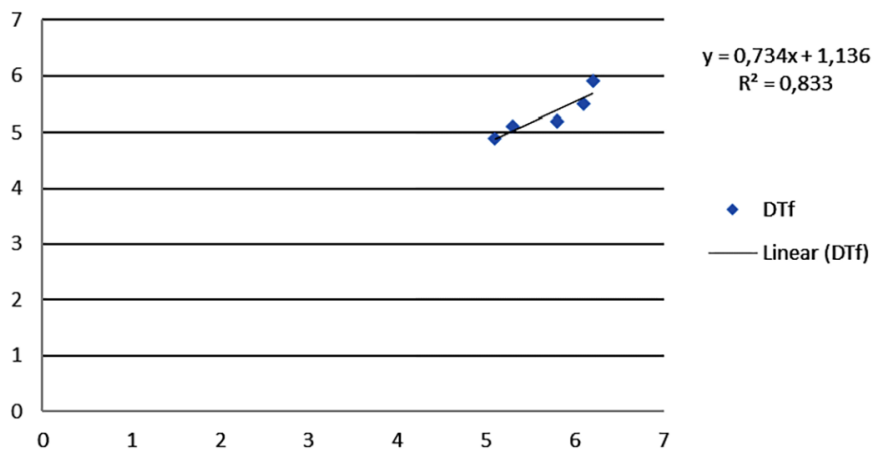

Fig.3. Linear correlation between the thoracic diameters in male and female capuchin monkeys.

Cardiac Diameter (Male versus Female)

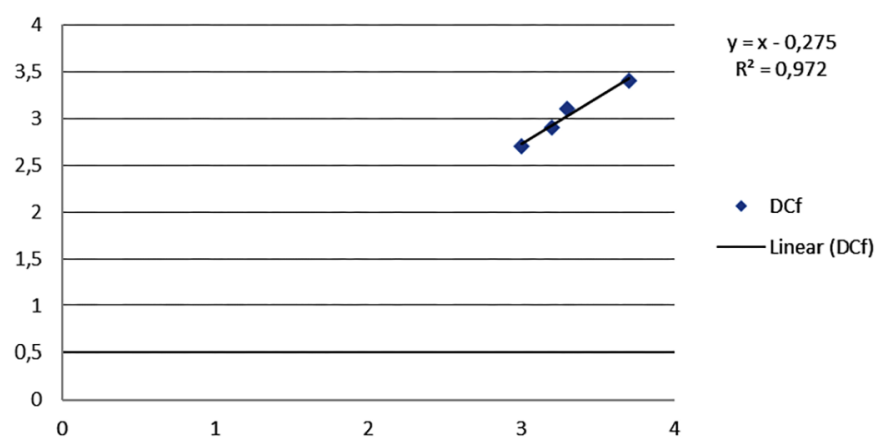

Fig.4. Linear correlation between the cardiac diameters in male and female capuchin monkeys.

The study of the correlations between the thoracic diameter $(y=0.734 x+1.136 . r=0.833)$ and heart diameter $(y=x-0.275 . r=0.972)$ between males and females showed strong interaction between these variables (Fig.3 and 4).

\section{DISCUSSION}

The morphological assessment of the thoracic cavity of the Cebus apella in our findings showed that the anatomic conformation varied little, similar to that observed in other nonhuman primates, such as Callithrix jacchus (Wagner \& Kirberger 2005), Chlorocebus sabaeus (Young et al. 2013) and Macaca mulata (Ji et al. 2013). This characteristic became essential to apply biometric tests that allowed discreet increases to be defined in the heart silhouette of these animals, enabling the early diagnosis of cardiovascular diseases (Schillaci et al. 2010).

VHS is a well-established technique in veterinary medicine (Jepsen-Grant et al. 2013) and correlates positively with the development of heart increases in companion animals (Guglielmini et al. 2012). However, there are few studies on wild animals using VHS as a diagnostic tool. Felkai et al. (2014) described the presence of residual pleural effusion, heart increase and cardiomegaly, associated to increases in the VHS values in Cercopithecus neglectus, confirmed later by echocardiographic examination. The VHS values found in our assessments (mean $9.25 \pm 0.32 \mathrm{v}$, between males and females) were similar to those assessed for the Callithrix jacchus $(9.42 \pm 0.44 \mathrm{v})$, described by Wagner \& Kirberger (2005). These authors, corroborating our findings, did not observe statistical difference for the VHS values between males and females in the species that they studied. Although there is difference in weight and size between males and females in the tufted capuchin, there is consensus in the literature available on the weak interaction between the body mass and the VHS values, both in companion animals and other nonhuman primates (Schillaci et al. 2008, Young 2012, Ji et al. 2013). Other monkey species, such as Aotus spp. (Knowlen et al. 2013) and Macaca fascicularis (Xie et al. 2014) have been widely studied in this sense. However, to our knowledge, to date only Alves et al. (2012) have standardized VHS values in the Cebus apella species.

The vertebral heart size is a widely accepted method to quantify the size of the heart silhouette and can provide information on the presence of cardiomegaly and congestive heart insufficiency, because it correlates positively with the myocardial function (Hammermeister et al. 1979, Hubbell et al. 1985, Kearney et al. 2002). The standardization of this index for the tufted capuchin in the present research $(0.55 \pm 0.04)$ showed normality values greater than those observed in humans (Dimopoulos et al. 2013). Although it is a cardio thoracic ratio compatible with installed heart disease (Gustafsson et al. 2003) and Solomon et al. (2005), the animals studied did not present clinical or radiographic signs compatible with heart insufficiency to any degree. Allied to this, data previously reported by Schillaci et al. (2009), in monkeys of the Macaca tonkeana (0.59) and Macaca nigra (0.58) species and by Xie et al. (2014) for Macaca fascicularis (0.58) were similar to our findings, suggesting that the primates present higher CTR values than those observed in humans. Similar to our studies, these authors did not find significant statistical difference between males and females regarding the CTR measurements, suggesting that there is little or no influence of gender on this variable for the species. Xie et al. (2013) further reported that the growth-promoted alterations did not show significant differences in the thoracic conformation and biometry in young males and females of the Macaca mulatta species. Nonhuman primates present heart diseases similar to those found in humans (Wolfe-Coote 2005, Liang et al. 2005). Advanced techniques such as computerized tomography and magnetic resonance are considered the gold standard in thoracic disease diagnosis, but are expensive and their use for non- human primates is still not global (Xie et al. 2014).

There is still no systematic study to acquire parameters measured in thoracic $x$-rays of tufted capuchin, making it essential to construct reference indices to base the analysis of the heart silhouette in the species.

The CTR calculated for the tufted capuchin studied, like 
the heart and thoracic diameters, showed little variation. These results reinforce the hypothesis that the CTR is sensitive to diagnose discreet variations in the heart silhouette of these animals, and early diagnosis of heart diseases is possible. Gustafsson et al. (2003) and Solomon et al. (2005) reported that increase in the heart chambers reflects a range of pathological processes that can affect the cardiovascular function: hypertrophy, dilation and heart remodeling, established markers in acquired heart diseases. Dimopoulos et al. (2013) demonstrated in humans that CTR greater than 0.55 is associated to cardiomegaly. These authors considered a CTR between 0.48 and 0.55 as a moderate heart increase index.

These reference data are scarce for nonhuman primates. Only Felkai et al. (2014) describe a CTR of 0.68 (68\%) for Cercopithecus neglectus with an acquired heart disease associated to $7-10 \%$ fractional shortening. In our studies, we observed strong interaction between the VHS and CTR values $(y=0.1069 x-0.4346$. $r=0.78)$, a relationship that has not yet been discussed in the literature for nonhuman primates. These values allowed us to infer that both the VHS and the CTR can be used as reliable measuring methods to assess the heart silhouette in tufted capuchin. Because CTR can be carried out in sternal decubitus (dorsoventral projection), animals with pleural or important pericardial effusion that do not accept very well lateral decubitus, can be preferentially studied by the vertebral heart size method.

\section{CONCLUSIONS}

The present study demonstrated that the CTR, until now only used in human medicine, when compared to the VHS (a cardiac index consolidated in veterinary medicine), showed positive correlation and clinical precision in its application.

In tufted capuchin, the animal model used in the present study, the CTR was shown to be a diagnostic and investigative tool, and is an option in the choice of a method to assess increases in heart silhouette in these animals.

Acknowledgements.- The authors thank the image diagnosis team at the University Veterinary Hospital (HVU-UFPI), in the name of Prof. Dr. João Macedo. They also thank the Coordenação de Aperfeiçoamento de Pessoal de Nível Superior (CAPES), for the master of science grant.

\section{REFERENCES}

Alves F.R., Costa F.R., Arouche M.M.S., Barros A.C.E., Miglino M.A., Vulcano L.C. \& Guerra P.C. 2007. Ultrasonographic evaluation of the urinary system, liver and uterus of Cebus apella monkey. Pesq. Vet. Bras. 27:377382.

Andrade M.C., Ribeiro C.T., Silva V.F., Molinaro E.M., Goncalves M.A., Marques M.A., Cabello P.H. \& Leite J.P. 2004. Biologic data of Macaca mulatta, Macaca fascicularis, and Saimiri sciureus used for research at the Fiocruz primate center. Mem. Inst. Oswaldo Cruz 99:581-589.

Buchanan J.W. 2000. Vertebral scale system to measure heart size in radiographs. Vet. Clin. North Am., Small. Anim. Pract. 30:379-393.

Dimopoulos K., Giannakoulas G., Bendavan I., Liodakis E., Petraco R., Diller G.P., Piepoli M.F., Swan L., Mullen M., Best N., Poole-Wilson P.A., Francis D.P. Rubens M.B. \& Gatzoulis M.A. 2013. Cardiothoracic ratio from posterior-anterior chest radiographs: a simple, reproducible and independente Market of disease severity and outcome in adults with congenital heart disease. Int. J. Cardiol. 166:453-457.
Felkai A., Vogelnest L., McNabb S., Allan G. \& Sangster C. 2014. Dilated cardiomyopathy in a De Brazza's monkey (Cercopithecus neglectus). J. Med. Primatol. 43:209-212.

Fukushima M., Saunders R.C., Mullarkey M., Doyle A.M., Mishkin M. \& Fujii N. 2014. An electrocorticographic electrode array for simultaneous recording from medial, lateral, and intrasulcal surface of the cortex in macaque monkeys. J. Neurosci. Methods 233:155-165.

Guglielmini C., Diana A., Santarelli G., Torbidone A., Di Tommaso M., Baron Toaldo M. \& Cipone M. 2012. Accuracy of radiographic vertebral heart score and sphericity index in the detection of pericardial effusion in dogs. J. Am. Vet. Med. Assoc. 241:1048-1055.

Gustafsson F., Torp-Pedersen C., Brendorp B., Seibaek M., Burchardt H. \& Kober L. 2003. Long-term survival in patients hospitalized with congestive heart failure: relation to preserved and reduced left ventricular systolic function. Eur. Heart. J. 24:863-780.

Hammermeister K.E., Chikos P.M., Fisher L. \& Dodge H.T. 1979. Relationship of cardiothoracic ratio and plainfilm heart volume to late survival. Circulation 59:89-95.

Hasan M.A., Lee S.L., Kim D.H. \& Lim M.K. 2012. Automatic evaluation of cardiac hypertrophy using cardiothoracic área ratio in chest radiograph images. Comput. Methods Programs Biomed. 105:95-108.

Hubbell F.A., Greenfield S., Tyler J.L., Chetty K. \& Wyle F.A. 1985. The impact of routine admission chest X-ray films on patient care. N. Engl. J. Med. 312:209-213.

Jepsen-Grant K., Pollard R.E. \& Johnson L.R. 2013. Vertebral heart scores in eight dog breeds. Vet. Radiol. Ultrasound 54:3-8.

Ji Y., Xie L., Liu S., Cheng K., Xu F., Li X., Wang T., Zhou Q., Fang L. \& Xie P. 2013. Correlation of thoracic radiograph measurements with age in adolescent Chinese rhesus macaques (Macaca mulatta). J. Am. Assoc. Lab. Anim. Sci. 52:78-82.

Kearney M.T., Fox K.A., Lee A.J., Prescott R.J., Shah A.M., Batin P.D., Lindsay S., Callahan T.S., Shell W.E., Eckberg D.L., Zaman A.G., Willams S., Neilson J.M. \& Nolan J. 2002. Predicting death due to progressive heart failure in patients with mild-to-moderate chronic heart failure. J. Am. Coll. Cardiol. 40:1801-1808.

Knowlen G.G., Weller R.E., Perry R.L., Baer J.F. \& Gozalo A.S. 2013. Hypertrophic cardiomyopathy in owl monkeys (Aotus spp.). Comp. Med. 63:279-287.

Lamb C.R. \& Boswood A. 2002. Role of survey radiography in diagnosing canine cardiac disease. Comp. Cont. Educ. Pract. Vet. 24:316-326.

Lamb C.R., Wikeley H., Boswood A. \& Pfeiffer D.U. 2001. Use of breed-specific ranges for the vertebral scale as an aid to the radiographic diagnosis of cardiac diseases in dogs. Vet. Rec. 230:1870-1876.

Lawler J.V., Endy T.P., Hensley L.E., Garrison A., Fritz E.A., Lesar M., Baric R.S., Kulesh D.A., Norwood D.A., Wasieloski L.P., Ulrich M.P., Slezak T.R., Vitalis E., Huggins J.W., Jahrling P.B. \& Paragas J. 2006. Cynomolgus macaque as an animal model for severe acute respiratory syndrome. Plos Medicine 3:677-686.

Liang S.L., Chin S.C., Yang H.L. \& Yeh L.S. 2005. Radiographic measurements of cardiac size in the Formosan monkeys. Taiwan. Vet. J. 31:85-91.

Litster A.L. \& Buchanan J.W. 2000. Vertebral scale system to measure heart size in radiographs of cats. J. Am. Vet. Med. Assoc. 216:210-214.

Michiue T., Ishikawa T., Sakoda S., Quan L., Li D.R., Kamilodai Y., Okazaki S., Zhu B.L. \& Maeda H. 2010. Cardiothoracic ratio in post-mortem chest radiography with regard to the cause of death. Leg. Med., Tokyo, 12:73-78.

Nakayama H., Nakayama T. \& Hamlin R.L. 2001. Correlation of cardiac enlargement as assessed by vertebral heart size and echocardiographic and electrocardiographic findings in dogs with evolving cardiomegaly due to rapid ventricular pacing. J. Vet. Intern. Med. 15:217-221.

Nimri L.F. \& Lanners H.N. 2014. Glomerulonephropathies in Plasmodium inui-infected rhesus monkey: a primate model and possible applications for human quartan malaria. Parasitology 15:1-8.

Reichle J.K. \& Wisner E.R. 2000. Non-cardiac thoracic ultrasound in 75 feline and canine patients. Vet. Radiol. Ultrasound 41:154-162.

Schillaci M.A., Jones-Engel L., Heidrich J.E., Benamore R., Pereira A. \& Paul 
N. 2008. Thoracic radiography of pet macaques in Sulawesi, Indonesia. J. Med. Primatol. 37:141-145

Schillaci M.A., Lischka A.R., Karamitsos A.A., Engel G.A., Paul N., Ramoula R., Rompisd A., Putrad A., Wandiad N.I. \& Jones-Engele L. 2010. Radiographic measurement of the cardiothoracic ratio in a feral population of long-tailed macaques (Macaca fascicularis). Radiography 16:163-166.

Schillaci M.A., Parish S. \& Jones-Engel L. 2009. Radiographic measurement of the cardiothoracic ratio in pet macaques from Sulawesi, Indonesia. Radiography 15:29-33.

Sharpe S.A., McShane H., Dennis M.J., Basaraba R.J., Gleeson F., Hall G., McIntyre A., Gooch K., Clark S., Beveridge N.E., Nuth E., White A., Marriott A., Dowall S., Hill A.V., Willams A. \& Marsh P.D. 2010. Establishment of an aerosol challenge model of tuberculosis in rhesus macaques and an evaluation of endpoints for vaccine testing. Clin. Vaccine Immunol. 17:1170-1182.
Solomon S.D., Anavekar N., Skali H., McMurray J.J., Swedberg K., Yusuf S., Granger C.B., Michelson E.L., Wang D., Pocock S. \& Pfeffer M.A. 2005. Influence of ejection fraction on cardiovascular outcomes in a broad spectrum of heart failure patients. Circulation 112:3738-3744.

Wagner W.M. \& Kirberger R.M. 2005. Radiographic anatomy of the thorax and abdomen of the common marmoset (Callithrix jacchus). Vet. Radiol. Ultrasound 46:217-224.

Wolfe-Coote S. 2005. The Laboratory Primate. Academic Press, San Diego, p.371-386.

Xie L., Zhou Q., Liu S., Wu Q., Ji Y., Zhang L., Xu F., Gong W., Melgiri N.D. \& Xie P. 2014. Normal thoracic radiographic appearance of the cynomolgus monkey (Macaca fascicularis). Plos One 9:1-6.

Young A.N., Du Plessis W.M., Rodriguez D. \& Beierschimitt A. 2013. Thoracic radiographic anatomy in vertet monkeys (Chlorocebus sabaeus). J. Med. Primatol. 42:310-317. 